\title{
Elementary tetrahelical protein design for diverse oxidoreductase functions
}

\author{
Tammer A Farid ${ }^{\# 1}$, Goutham Kodali"1, Lee A Solomon ${ }^{\# 1}$, Bruce R Lichtenstein ${ }^{1,2}$, Molly M \\ Sheehan ${ }^{1}$, Bryan A Fry ${ }^{1}$, Chris Bialas ${ }^{1}$, Nathan M Ennist ${ }^{1}$, Jessica A Siedlecki ${ }^{1}$, Zhenyu \\ Zhao $^{1}$, Matthew A Stetz ${ }^{1}$, Kathleen G Valentine ${ }^{1}, \mathbf{J ~ L ~ R o s s ~ A n d e r s o n ~}^{1,3}$, A Joshua Wand ${ }^{1}$, \\ Bohdana M Discher ${ }^{1}$, Christopher C Moser ${ }^{1}$, and $\mathbf{P}$ Leslie Dutton ${ }^{1,{ }^{*}}$ \\ ${ }^{1}$ Department of Biochemistry and Biophysics, Johnson Research Foundation, University of \\ Pennsylvania, Philadelphia, Pennsylvania, USA \\ ${ }^{2}$ Max Planck Institute for Developmental Biology, Tübingen, Germany \\ ${ }^{3}$ School of Biochemistry, University of Bristol, Bristol, UK \\ \# These authors contributed equally to this work.
}

\begin{abstract}
Emulating functions of natural enzymes in man-made constructs has proven challenging. Here we describe a man-made protein platform that reproduces many of the diverse functions of natural oxidoreductases without importing the complex and obscure interactions common to natural proteins. Our design is founded on an elementary, structurally stable 4-a-helix protein monomer with a minimalist interior malleable enough to accommodate various light- and redox-active cofactors and with an exterior tolerating extensive charge patterning for modulation of redox cofactor potentials and environmental interactions. Despite its modest size, the construct offers several independent domains for functional engineering that targets diverse natural activities, including dioxygen binding and superoxide and peroxide generation, interprotein electron transfer to natural cytochrome $c$ and light-activated intraprotein energy transfer and charge separation
\end{abstract}

\footnotetext{
() 2013 Nature America, Inc. All rights reserved.

*dutton@mail.med.upenn.edu.
}

\section{Author Contributions}

T.A.F. contributed to the design and characterization of maquettes $\mathbf{A}, \mathbf{E}, \mathbf{J}, \mathbf{H}$ and $\mathbf{B} ;$ G.K. designed, expressed, purified and characterized maquettes $\mathbf{C}, \mathbf{L}, \mathbf{D}, \mathbf{K}$ and $\mathbf{F}$ and contributed to all of the experiments performed with these maquettes as well as the writing of the manuscript; L.A.S. performed the redox titrations, developed and characterized maquette $\mathbf{G}$ and performed $\mathrm{CO}$ and $\mathrm{O}_{2}$ kinetics on maquette $\mathbf{A}$ as well as assisted in the writing of the manuscript; B.R.L. contributed to the monomeric maquette design as well as experimental design and interpretation; M.M.S. designed and purified maquette I and measured superoxide production, lowtemperature spectra and oxyferrous state kinetics; B.A.F. measured electron transfer from $\mathbf{A}$ to cytochrome $c$; C.B. synthesized and characterized flavomaquettes; N.M.E. performed synthetic chlorin binding affinity measurements and contributed to protein design; J.A.S. contributed to heme and Zn porphyrin binding affinities of $\mathbf{C}$ and $\mathbf{J}$; Z.Z. contributed to protein design; B.M.D. contributed to experimental designs and manuscript writing; M.A.S., K.G.V. and A.J.W. contributed to the NMR characterization of maquettes;

J.L.R.A. contributed to $\mathrm{CO}$ and $\mathrm{O}_{2}$ ligand kinetics for maquette A. C.C.M. designed and operated transient spectroscopy equipment for photolysis and light-induced electron transfer and contributed substantially to manuscript writing; P.L.D. conceived and designed experiments and contributed substantially to manuscript writing.

Competing financial interests

The authors declare no competing financial interests.

Additional Information

Supplementary information is available in the online version of the paper. Reprints and permissions information is available online at http://www.nature.com/reprints/index.html. Correspondence and requests for materials should be addressed to P.L.D. 
approximating the core reactions of photosynthesis, cryptochrome and photolyase. The highly stable, readily expressible and biocompatible characteristics of these open-ended designs promise development of practical in vitro and in vivo applications.

In his 1902 Nobel lecture ${ }^{1}$, Emil Fischer described a future in which man-made enzymes would be put to work for the benefit of society. But the translation of modern mechanistic descriptions of natural enzymes into practical engineering guidelines for construction of man-made enzymes remains elusive $\mathrm{e}^{2-4}$. The complexity of proteins accumulated during repeated blind natural selection ${ }^{5,6}$ obscures the identity of what amino acids support any one function and what functional roles are played by any one amino acid. Hence, the common practice of importing mimicked natural protein sequences or structural motifs into manmade constructions does not assure successful import of a selected function.

Our strategy to construct man-made enzymes seeks to minimize undesirable complexity and increase engineering freedom by integrating two sets of design principles. First, we begin with a protein framework that is drawn from first-principle studies on the folding of repeating amino acid heptads of 4 -a-helical bundles ${ }^{7}$ free of intended function and that is simple enough that the chemical functionalities of each amino acid are few and largely understood. Second, within this frame, we secure cofactors according to general functional engineering principles of the natural oxidoreductase family of enzymes ${ }^{8}$ without resorting to mimicry of any one natural enzyme. These electron-transfer proteins represent more than a quarter of named natural enzymes and cover a large and diverse range of functions of direct relevance to practical medical and world energy problems. The ability to recreate and extend these natural functions in customizable, and economical man-made units would have wideranging benefits.

Earlier work exploring oxidoreductase functions arising from cofactors inserted into firstprinciples $a$-helical frames (maquettes ${ }^{9}$ ) has yielded a set of proof-of-principle demonstrations of cofactor assembly strategies and simple functions representative of the key subclasses of the oxidoreductase family. This includes light- and redox-active cofactors supporting oxidation and reduction ${ }^{10}$, proton coupling ${ }^{11}$, electrochemical charge coupling ${ }^{12}$ and ligand exchange ${ }^{13}$, including the generation of a stable oxyferrous heme state familiar in oxygen transport by globins ${ }^{14}$. However, the sequence duplication of these symmetrical homotetrameric and homodimeric structures fails to support the diverse, multiple cofactor assembly needed for more sophisticated oxidoreductases.

This problem is answered by transforming a homodimer into a single-chain 4-a-helical protein introduced here (Fig. 1a) that preserves earlier physical and functional properties. We go on to exploit these properties as incisive tools for analyzing the degree of physical interdependence between domains within the maquette and expose the roles of individual amino acids in supporting structure-function relationships. The analysis reveals a versatile, stable monomer that exploits sequence asymmetry for the design and engineering of diverse advanced oxidoreductase functions operating with activities comparable to natural counterparts. 


\section{RESULTS}

\section{Loop selection}

The homodimeric, helix-loop-helix design was transformed into the single-chain helix-loophelix-loop-helix-loop-helix design (Fig. 1a) by eliminating the disulfide linking cysteines in the loops and connecting the $\mathrm{C}$ terminus of one unit to the $\mathrm{N}$ terminus of the other. Previous efforts by others have shown that man-made helical bundles can be grafted with natural loop sequences ${ }^{15}$ and that natural helical sequences can be grafted with man-made glycine-rich loops ${ }^{16-18}$. The new loop connecting helices 2 and 3 has been tested with lengths of 9 and 11 amino acids ( $\mathbf{A}$ and $\mathbf{B}$ in Table 1); both lengths yield monomers with no sign of multimers or aggregates below $150 \mu \mathrm{M}$. For simplicity, we kept the same 9-amino-acid length for all of the loops except for $\mathbf{B}$. The 132-amino-acid-long single-chain sequence $\mathbf{A}$ (Table 1) uses a simplified subset of 13 amino acids, has a molecular mass of $\sim 15 \mathrm{kDa}$ and readily overexpresses in Escherichia coli.

\section{combined functional and structural analysis}

Earlier maquettes established a range of functions related to heme B (Fe-protoporphyrin IX, common in natural oxidoreductases). We took the unusual step here of exploiting these functional properties to survey and map physical interdependencies between secondary and tertiary structures in the monomer.

Binding interdependencies between heme ligation sites-The monomer $\mathbf{A}$ has been designed to maintain bis-histidine ligation sites at positions analogous to the tethered dimer maquette ${ }^{14}$ (Fig. 1). An earlier apo crystal structure ${ }^{19}$ revealed that a substantial $\sim 55^{\circ}$ rotation of the helices is required for bis-histidine ligation of the heme. Measurements of the affinity of heme B for bis-histidine ligations across both helices 1 and 3 as well as 2 and 4 of monomer A revealed indistinguishable dissociation constants ( $K_{\mathrm{D}}$ values) of the two hemes in the low nanomolar range $(0.2-2 \mathrm{nM})$, indicating little if any negative interdependency from structural or charge coupling of the like charged cationic ferric hemes. Another estimate of the magnitude of the interaction between the heme-binding sites in $\mathbf{A}$ was obtained after replacing one histidine with alanine ( $\mathbf{C}$ in Table 1), effectively disabling one of the heme-binding sites. The now-unique $K_{\mathrm{D}}$ weakens slightly to $12 \mathrm{nM}$, corresponding to $\sim 1-3 \mathrm{kcal} \mathrm{mol}^{-1}$ of interaction, which is much less than the $12-15 \mathrm{kcal} \mathrm{mol}^{-1}$ released on ligation of heme to either site. $K_{\mathrm{D}}$ measurements for $\mathbf{A}$ and variants are detailed in Supplementary Results, Supplementary Figures 2 and 5-8.

\section{Independent heme-induced thermal stabilization and structuring of helix pairs}

-For practical purposes, it is important to maintain high thermal stability of the maquettes regardless of the nature of the functions added. By using temperature-dependent $\mathrm{CD}$ to monitor the thermal stability of the a-helical structure of maquette $\mathbf{A}$ and variants, we found that even minor substitutions in the interior of the apo form provide substantial thermal stabilization. Figure 2a shows that replacement of all four histidine residues of $\mathbf{A}$ raises the melting transition temperature $\left(T_{\mathrm{m}}\right)$ from $37{ }^{\circ} \mathrm{C}$ to $55^{\circ} \mathrm{C}$ (with alanine, maquette $\mathbf{D}$ ) or to 95 ${ }^{\circ} \mathrm{C}$ (with phenylalanine, maquette $\mathbf{E}$ ), consistent with the destabilizing effects of interior histidines relative to these aliphatic and aromatic residues. 
The $T_{\mathrm{m}}$ can also be raised by adjusting exterior charges to add favorable intra- and interhelical salt bridges. Adding salt bridge-forming lysines and arginines to two of the helices (maquette $\mathbf{F}$ ) raises the $T_{\mathrm{m}}$ to $48^{\circ} \mathrm{C}$. Making similar adjustments to all four of the helices (maquette $\mathbf{G}$ ) raises the $T_{\mathrm{m}}$ to $55^{\circ} \mathrm{C}$. Figure $2 \mathrm{~b}$ compares these effects to the wellknown effect of adding a terminating hydrogen-bonding $\mathrm{N}$-terminal $\mathrm{cap}^{20}$ (maquette $\mathbf{H}$ ). Although these results indicate substantial control over thermal stability of the apo maquettes, bis-histidine ligation of heme overrides these stabilizing effects in all of the heme-binding sequences; after two hemes are ligated, all of them display a cooperative single transition with a $T_{\mathrm{m}}$ close to $72{ }^{\circ} \mathrm{C}$ (Fig. 2c).

Heme-ligation dependent thermal unfolding also provides evidence for the structural independence of the two helical pairs that bis-histidine ligate heme. With just one heme ligated to $\mathbf{A}$, the transition splits into two nearly equal steps with $T_{\mathrm{m}}$ values at $38^{\circ} \mathrm{C}$ and 72 ${ }^{\circ} \mathrm{C}$, one similar to the apo transition and the other to the two-heme transition. This split is not a result of cooperative binding of the two hemes because an obligate single hemebinding maquette $\mathbf{C}$ (H42A mutation) slightly raises the $T_{\mathrm{m}}$ from $37{ }^{\circ} \mathrm{C}(\mathbf{A})$ to $39^{\circ} \mathrm{C}$ (Fig. 2c) in the apo form but retains two transitions of $\mathbf{A}$ on addition of a single heme. Thus the thermal stability induced in each helix pair of $\mathbf{A}$ upon heme ligation occurs largely independently of the occupancy of the heme in the other helical pair. Such independence makes it easier to adjust one cofactor-binding region without compromising the properties of another nearby cofactor-binding domain, a demonstration of independence rare in natural proteins.

NMR provides further evidence that helix pairs form largely independent substructures within the maquettes. The chemical shifts in the two-dimensional HSQC analysis on ${ }^{15} \mathrm{~N}$ labeled maquettes for the apo form of A disperse poorly (Fig. 3a), demonstrating the absence of unique tertiary structure on the NMR timescale. The histidine-free variant maquette $\mathbf{E}$, which eliminates heme ligation, also remains unstructured upon heme addition (Fig. 3b). NMR structuring of $\mathbf{A}$ only becomes conspicuous on ligation of heme, as has been shown with the tethered homodimer ${ }^{21}$. The indistinguishable $K_{\mathrm{D}}$ values for heme at the two sites make it difficult to discriminate helical structuring associated with each particular heme-binding site. Nevertheless, the pattern of progressive structuring on heme binding in Figure $3 \mathrm{c}, \mathrm{d}$ is consistent with one heme imposing structural constraints on one helix pair and the second heme imposing similar constraints on the second helix pair.

Heme redox potentials and electrochemical charge coupling-Redox midpoint potentials $\left(E_{\mathrm{m}}\right)$ are sensitive probes of electrochemical environment. The $E_{\mathrm{m} 8}(\mathrm{pH} 8)$ values of the two hemes bound to $\mathbf{A}$ are indistinguishable at $-290 \mathrm{mV}$, proving the absence of substantial charge interactions between the two cationic ferric hemes and indicating similar electrochemical environments. The lack of charge-charge redox interaction between hemes in $\mathbf{A}$ is most likely a consequence of the relatively long distance between the ferric irons of the hemes ( $25 \AA$ ). The $E_{\mathrm{m} 8}$ of a single heme bound to $\mathbf{A}$ or the obligate $\mathbf{C}$ with single heme is $-259 \pm 7 \mathrm{mV}$ (Table 1 and Supplementary Fig. 4), indicating a minor $30 \mathrm{meV}$ or $0.7 \mathrm{kcal}$ $\mathrm{mol}^{-1}$ interaction between the two heme sites. These results are consistent with $K_{\mathrm{D}}$ and NMR measurements. 
The heme potentials in natural oxidoreductases are altered by exterior charges, salt bridges and hydrogen bonds near the heme. In testing such influence on a heme in a maquette, we maintained exterior charges equal among the four helices but shifted the net charge from -16 (A) to +11 (G). This raised the $E_{\mathrm{m} 8}$ values of both hemes from $-290 \mathrm{mV}$ to $-150 \mathrm{mV}$, consistent with expectations (Table 1 and Supplementary Figs. 3 and 4). Creating an unequal charge distribution by changing the net charge of the helical pair associated with one heme to +4 and leaving the other at $-8(\mathbf{F})$ causes a split in the Nernst transition, yielding $E_{\mathrm{m} 8}$ values of $-224 \mathrm{mV}$ and $-150 \mathrm{mV}$. The impact of such changes in $E_{\mathrm{m} 8}$ values of the maquette is in line with work done on the well-studied native cytochrome $c^{22,23}$ and indicates that the maquette properties follow the trends of natural redox proteins. However, the demonstration that the maquette can withstand such massive alterations in external charge patterning without loss of stability (Fig. 2b) is unprecedented.

Interdependencies between the heme-ligating helix pairs binding $\mathrm{O}_{2}$-The formation and lifetime of an oxyferrous heme state provides a sensitive probe of hemeligand affinities, exchange dynamics and water accessibility to the heme site $^{13}$. Crucial for successful oxygen binding is the introduction of strain into the helices during the modeled mechanical rotation upon bis-histidine ligation of the heme ${ }^{14}$. This is achieved by placing glutamates at the heptad b positions ${ }^{7}$, which rotate upon heme ligation toward the hydrophobic interior of the protein where the partially buried glutamates become energetically unfavorable ${ }^{14}$. The resolvation of the glutamates is considered the driving force energy for histidine displacement by added ligands ${ }^{14}$.

Figure 4 shows that $\mathbf{A}$ retains the oxygen-binding function of the tethered homodimer maquette ${ }^{14}$. A supports two separate oxy- or carboxyferrous heme-binding sites, despite the acknowledged modeled rotational action and obligatory conformational changes that accompany heme histidine- $\mathrm{O}_{2}$ (or $\mathrm{CO}$ ) ligations (Fig. 4a). Indeed, $\mathbf{A}$ with two hemes bound neatly doubles the yields and absorbance of carboxyferrous and oxyferrous heme states of a single heme bound within 5\%; Figure 4a shows the one-heme oxy spectrum plotted at twice the vertical scale and nearly overlaps with the two-heme oxy spectrum. Furthermore, kinetic examination of $\mathbf{A}$ with two hemes bound at $+15{ }^{\circ} \mathrm{C}$ demonstrates that $\mathrm{O}_{2}$ binding transforms bis-histidine-ligated ferrous heme into the oxyferrous heme state with a single exponential lifetime of $196 \pm 2 \mathrm{~ms}$ (Fig. 4b). This state slowly decays via electron transfer to bishistidine-ligated ferric heme with a lifetime of $14.3 \pm 0.1 \mathrm{~s}$. The reaction time courses of the two hemes in the separate helix pairs are indistinguishable. Similar measurements on the single heme in A yield formation and decay lifetimes of $90 \pm 3 \mathrm{~ms}$ and $14.3 \pm 0.1 \mathrm{~s}$.

Evidently, the single heme in $\mathbf{A}$ has a lower kinetic barrier for $\mathrm{O}_{2}$ binding, equivalent to $\sim 0.6$ $\mathrm{kcal} \mathrm{mol}{ }^{-1}$ of interaction energy between the heme-binding sites. However, the identical oxyferrous lifetime provides proof that resistance to water access to oxyferrous heme in the bundle interior is independent of the number of hemes bound.

These characteristics of $\mathbf{A}$ are comparable with the rate of formation of the oxyferrous heme state and stability found in natural hexacoordinate globins typified by human neuroglobin ${ }^{24,25}$. The thermal stability of $\mathbf{A}$ also closely matches that of natural 
hexacoordinate globins ${ }^{26}$. However, it differs from these natural counterparts in supporting more than double the oxygen-binding capacity on a protein mass basis.

\section{Extending the diversity of oxidoreductase functions}

The above structure-function analyses set the stage to explore the molecular versatility of $\mathbf{A}$ for a range of more sophisticated diverse oxidoreductase functions within the same protein or one with only minimal sequence alterations.

Interprotein electron transfer between natural and man-made proteins-Natural cytochrome $c$ is an archetype of physiologically ubiquitous diffusive interprotein electron transport that exploits a positive patch of lysines around its heme edge to dock with complementary, negative patches on its native redox partners ${ }^{27-29}$. Figure $4 \mathrm{~d}$,e demonstrates that the reduced form of the negatively charged $\mathbf{A}\left(E_{\mathrm{m} 8}-290 \mathrm{mV}\right)$ transfers an electron to oxidized cytochrome $c\left(E_{\mathrm{m} 8}=+270 \mathrm{mV}\right)^{29}$, a highly favored reaction $\left(\Delta G^{\circ}-12.9 \mathrm{kcal}\right.$ $\left.\mathrm{mol}^{-1}\right)$ with a bimolecular rate-constant of $2 \times 10^{7} \mathrm{M}^{-1} \mathrm{~s}^{-1}\left( \pm 5 \times 10^{6}\right)$, identical to that reported for neuroglobin, similar to allied hexa-coordinate globins ${ }^{27}$ and typical of diffusive electron transport in respiratory and photosynthetic energy conversion chains ${ }^{28}$.

Diverse globin functions-The last decade revealed that the natural hexacoordinate globin family performs diverse functions beyond those familiar in the related pentacoordinate hemoglobins ${ }^{25}$. Although hexacoordinate globins engage in reversible $\mathrm{O}_{2}$ binding, others rapidly promote electron transfer to $\mathrm{O}_{2}$. Remarkably, both classes rapidly transfer electrons to mitochondrial cytochrome $c$ and most likely engage in cell regulation.

The bis-histidine ferrous heme of globin GLB-26 from Caenorhabditis elegans does not bind oxygen; it undergoes oxidation well before ligand exchange in a superoxide-generating $\mathrm{O}_{2}$ reduction identified as outer-sphere electron tunneling ${ }^{25}$. We find that the stable, reversible, $\mathrm{O}_{2}$-binding monomer $\mathbf{A}$ can be transformed into an effective superoxide generator in two mechanistically distinct ways. One way relieves rotational strain of the helix upon heme binding ${ }^{14}$ by replacing three glutamates per helix with alanines $(\mathbf{I})$. This creates a larger energetic barrier for the distal histidine to dissociate, preventing $\mathrm{O}_{2}$ from competitive binding to the ferrous iron, as found in GLB-26 (ref. 25). Thus, ferrous heme in I undergoes oxidation ( $t_{1 / 2} 0.15 \mathrm{~s}$; Fig. $4 \mathrm{c}$ and Supplementary Fig. 42), concomitant with superoxide formation observed by the chemiluminescent 2-methyl-6-(4-

methoxyphenyl)-3,7-dihydroimidazo[1,2-a] pyrazin-3-one hydrochloride (MCLA) probe ${ }^{30}$. Superoxide is well known to rapidly disproportionate to produce peroxide ${ }^{31}$. This result sharply contrasts with $\mathbf{A}$, which creates superoxide at levels below the MCLA detection threshold and below levels regarded as physiologically relevant for oxidative damage ${ }^{30}$. Another way is to permit water access to the oxyferrous heme state in the protein. H-D exchange, done on an earlier maquette, indicated rapid water access into the interior of the maquette ${ }^{13,21,32}$. Reanalysis of this maquette reveals a brief but detectable oxyferrous heme state decay with a $t_{1 / 2}$ of less than $0.1 \mathrm{~s}$ (Supplementary Fig. 43) accompanied by production of reactive oxygen species, consistent with oxygen-heme binding followed by a watercatalyzed inner-sphere electron transfer. These $t_{1 / 2}$ values compare well with reported $t_{1 / 2}$ 
values of $0.25 \mathrm{~s}$ for ferrous heme oxidation in GLB-26 and $0.1 \mathrm{~s}$ for superoxide generation by the NADPH oxidase (NOX) in neutrophils ${ }^{33}$.

Favorable free energies are important for spontaneous generation of superoxide. The $E_{\mathrm{m} 8}$ values of $\mathbf{A}(-290 \mathrm{mV})$ are in the same range as that for GLB-26 $(-192 \mathrm{mV}, \mathrm{pH} 7)^{25}$ and $\operatorname{NOX}(-225 \mathrm{mV} \text { and }-265 \mathrm{mV}, \mathrm{pH} 7)^{33}$ and are lower than that for the operative oxygensuperoxide couple $(-160 \mathrm{mV}, \mathrm{pH} 7)^{31}$, making each of these reactions favorable. This contrasts with the $E_{\mathrm{m} 7}$ value of $-129 \mathrm{mV}$ (ref. 25) for neuroglobin that makes the reaction unfavorable.

Photochemical charge separation-Multicofactor oxidoreductase functions common in the energy conversions of natural photosystems, including photosynthetic reaction centers and blue light-activated flavoproteins ${ }^{34,35}$, require cofactor site specificity. Different metalcontaining tetrapyrrole cofactors display sufficiently distinct inherent ligation chemistries to provide site specificity during cofactor self-assembly (Fig. 5a). The central Fe of heme strongly selects hexacoordinate bis-histidine ligation over single pentacoordinate histidine ligation, whereas $\mathrm{Mg}$ or $\mathrm{Zn}$ tetrapyrroles, common light-activatable cofactors, strongly ligate a single histidine. These distinctions guarantee site specificity for Fe as well as $\mathrm{Mg}$ or $\mathrm{Zn}$ tetrapyrrole assembly in maquettes. Thus conversion of a bis-histidine heme-binding site in A to a single histidine site by replacing a histidine with alanine or phenylalanine $(\mathbf{C}, \mathbf{J})$ selects for a light-activatable $\mathrm{Zn}$ protoporphyrin IX (ZnP), which binds a one heme-ligated $\mathbf{J}\left(\mathrm{ZnP} K_{\mathrm{D}}=3.2 \mu \mathrm{M}\right)$ with a protein to cofactor stoichiometry of 1:1:1. The malleable interior of heme-bound $\mathbf{C}$ accommodates a synthetic chlorophyll analog $\left(\mathrm{ZnC}^{36}\right)$ with bulky ring substituents $\left(\mathrm{ZnC} K_{\mathrm{D}}=800 \mathrm{nM}\right)$. Maquette malleability and versatility extends to the use of nontet-rapyrrole light-activatable and redox cofactors. For instance, $\mathbf{K}$ contains only one bis-histidine heme-binding site and includes a cysteine that can be covalently coupled to flavins and other cofactors.

\section{Light-activated electron-transfer between Zn porphyrin and heme-Light} activation of $\mathrm{ZnP}$ in $\mathbf{J}$ generates with high-quantum efficiency a long-lived triplet excited state $\left({ }^{3} \mathrm{ZnP} *\right)$ that is capable of reducing the heme. Our tunneling expression data ${ }^{8,37,38}$ indicate that back electron transfer from the photoreduced heme to the oxidized $\mathrm{ZnP}^{+}$ ground state is expected to be rapid in these two cofactor photochemical systems; however, adding a sacrificial electron donor such as aniline or EDTA reduces the $\mathrm{ZnP}^{+}$cation and traps the heme-reduced state, as shown by continuous illumination (Fig. 5b). Transient absorption spectra confirm the expected electron-transfer events (Fig. 5a): after excitation with a 550-nm laser pulse, the formation and decay of ${ }^{3} \mathrm{ZnP} *$ was monitored by absorbance spectra from $10 \mathrm{~ns}$ to $1 \mathrm{~s}$. The $150 \mathrm{~s}^{-1}$ decay rate of the ${ }^{3} \mathrm{ZnP} *$ state was increased to 1,200 $\mathrm{s}^{-1}$ upon ligation of heme. The shorter lifetime of the triplet state indicates an intraprotein electron-transfer rate from ${ }^{3} \mathrm{ZnP} *$ to heme $\mathrm{Fe}^{3+}$ of $1,100 \mathrm{~s}^{-1}$. In addition, with aniline present, a noticeable fraction of the heme is trapped in a reduced state to reveal at $30 \mathrm{~ms}$ a classic heme redox difference spectrum. Given the position of the ligating histidine residues on the helices of $\mathbf{J}$, the edge-to-edge distance between the two porphyrins is estimated to be $\sim 19.3 \AA$ A. With a driving force for charge separation from ${ }^{3} \mathrm{ZnP} *$ to heme of about $0.52 \mathrm{eV}$, this observed rate is consistent with electron tunneling with a reasonable reorganization 
energy of about $0.9 \mathrm{eV}$ (ref. 38). Charge recombination to the ground state is then expected to be about three times faster, consistent with the small but noticeable amount of reduced heme observed in the transient absorption spectra.

Light-activated Zn-chlorin electron transfer-620-nm laser light activates the chlorin $\mathrm{ZnC}$ in $\mathbf{C}$ and creates a triplet excited state, ${ }^{3} \mathrm{ZnC}^{*}$, that is weaker in reducing potential and decays more rapidly than $\mathrm{ZnP}$. Nevertheless, Figure 5a shows that the chlorin triplet decays faster with heme $\left(24,000 \mathrm{~s}^{-1}\right)$ than without heme $\left(9,900 \mathrm{~s}^{-1}\right)$, indicating a $\sim 14,000 \mathrm{~s}^{-1}$ intraprotein electron transfer rate. Compared to the $\mathrm{Zn}$ porphyrin, the larger chlorin macrocycle apparently extends further toward the heme, speeding electron transfer by shortening the edge-to-edge electron-transfer distance by $\sim 2 \AA$.

Light-activated flavin electron-transfer-K includes a single cysteine at amino acid position 50 in helix 2, providing better electron transfer control through one sulfur site for the covalent attachment of synthetic 8-bromoriboflavin, unlike in earlier symmetric homodimeric maquettes that unavoidably accommodated two cysteine sites ${ }^{10}$. This equips the maquette with a blue absorbing cofactor $(475 \mathrm{~nm}$ ) that is $\sim 0.5 \mathrm{eV}$ more energetic than $\mathrm{ZnP}$ or $\mathrm{ZnC}$. The triplet state of light-excited flavins is well known to photooxidize added sacrificial reductant EDTA ${ }^{39}$. The light-induced difference spectra in Figure 5c show that the photoreduced flavin in turn reduces heme by intraprotein electron transfer.

Chlorin-initiated energy transfer-These maquettes also bind other chlorins with different substituents around the macrocycle and different absorption spectra, such as $\mathrm{Zn}$ pyropheophorbide-a. By binding two different light-activatable chromophores in the same maquette, light activation of the blue-absorbing chromophore results in energy transfer to the red-absorbing chromophore, a function akin to the antennae light-harvesting system that is a prelude to charge separation in photosynthesis. This process is especially evident when the chromophores have substantially different spectra. An example of energy transfer between Zn-pyropheophorbide-a and a covalently linked chromophore, Alexa Fluor 750 (a histidine at position 112 is replaced with cysteine in $\mathbf{L}$ ) is shown in Supplementary Figures 13-15.

\section{DISCUSSION}

Our results demonstrate that the combined guidelines drawn from first-principle protein assembly and natural oxidoreductase engineering provide a palette of creative strategies for the construction of a diverse range of man-made oxidoreductase functions. The functions selected here to test the palette potential and exercise the capacity of the monomer as a design and engineering platform-electron transport, primary steps in oxidative catalysis and the steps primary to photochemical charge separation-represent the core reactions of the natural oxidoreductases. With a single chain, the direct design maquette approach $^{9,14,40,41}$ gains asymmetric design choices, reduces ambiguity in the essential assignment of the roles of individual amino acids and enhances control over complexity and domain interdependence, all of which are advantageous for engineering progressive development of function. Distinctly different functions can be realized with minimal change, sometimes as small as one amino acid. The approach complements other protein design 
methods that have explored combinatorial ${ }^{18,42-44}$ and computational ${ }^{45-47}$ techniques and reengineering of natural proteins ${ }^{48}$, targeting single functions modeled on natural oxidoreductases.

Despite its small size, the single-chain maquette reveals the presence of operationally distinct design domains that can be engineered separately. These domains include the interior of paired helices 1 and 3 and the interior of paired helices 2 and 4 as well as the external charged surfaces; loop regions may also operate as mostly independent domains ${ }^{49}$. The functional evidence for separate domains is well complemented by CD-monitored thermal stabilities of the secondary a-helices and NMR views of the tertiary structuring. Even with substantial conformational changes associated with helical rotation on heme binding and ligand exchange, including a 3-unit $\Delta \mathrm{p} K_{\mathrm{a}}$ glutamate-linked proton coupling to heme oxidation-reduction ${ }^{11}$, adjacent helical pairs are serviceably independent. Other cofactor-ligating schemes may break domains along different lines.

The basis for separate domains may be found in the unnatural design simplicity and the relatively straight helices ${ }^{19}$ united only by relatively weak van der Waals interactions. These suppress specific interhelical interactions and result in a slippery interface ${ }^{12}$ unless intentionally augmented by stronger interhelical bonds ${ }^{19,21}$. In this regard, the 12 - to 15 -kcal $\mathrm{mol}^{-1}$ of the bis-histidine heme ligation in A provides the driving force to induce separate structuring and enhances stability of each helix pair. The same unnatural simplicity of the sequences provides our maquettes with exteriors with an uncommonly high tolerance to changes in charge and polarity and interiors malleable enough to structure around a wide variety of ligated cofactors of different shapes, sizes and patterns of polarity. This ability to independently and combinatorially replace cofactors in one helical pair without hindering assembly in another and with minor alterations to change functions in different sites leads to ready multiplication of functional diversity. These characteristics are entirely unlike natural proteins (where there is no design and the alteration of any part can easily have unintended consequences elsewhere) and deliver a versatile engineering platform amenable to progressive design of increasingly sophisticated function.

It is clear that the functions supported in the maquettes, with characteristics close to their natural counterparts, do not require the atomistic structural precision so often presumed essential when examining the crystal structures of natural oxidoreductases. Various natural globin-like functions proceed within the confines of a heme-ligating a-helix pair without a globin fold. Suppression of the penetration of water into the interior of the monomer to stabilize the oxyferrous heme state does not require a well-formed tertiary structure. Interprotein electron transfer with cytochrome $c$ proceeds with physiological rate constants without a precise docking pattern of surface charges. In addition, $\AA$-level control is not required for managing intraprotein electron tunneling; rates between cofactors ${ }^{38}$ can be readily adjusted at a level of precision adequate to guide the sequence of electron transfers from nanoseconds to milliseconds.

Besides the challenge of advancing function to cover the more difficult chemical transformations performed by nature, there stands the challenge of achieving control over specific oxidoreductase functions inside a living cell. In vivo functionality of man-made 
proteins has already been demonstrated with a large combinatorial library of monomeric tetrahelical proteins that rescue various knockout strains of $E$. coli ${ }^{50}$. More recently, a maquette related to sequence $\mathbf{A}$ has been integrated with maturation enzymes inside $E$. coli to post-translationally modify heme $\mathrm{B}$ into a covalently linked heme $\mathrm{C}$ ligated to the maquette (Anderson, J.L.R. et al., data not shown). This in vivo work points to the feasibility of moving beyond Fischer's original vision and integrating man-made proteins with cellular metabolism.

\section{ONLINE METHODS}

\section{Materials}

All of the tetrapyrroles except $\mathrm{ZnC}$ were purchased from Frontier Scientific; $\mathrm{D}_{2} \mathrm{O}$ and ${ }^{15} \mathrm{NH}_{4} \mathrm{Cl}$ were from Cambridge Isotope Laboratories. All of the other reagents were purchased from Fisher Scientific or Sigma.

\section{Protein expression and purification}

Synthetic genes were obtained from DNA2.0 in PJ414 vector or subcloned into the pET32b(+) vector (Novagen) by PCR. The protein was expressed as a thioredoxin fusion with a His tag in E. coli BL21 (DE3) RIL cells (Stratagene) for $5 \mathrm{~h}$ at $37{ }^{\circ} \mathrm{C}$ after induction with $0.5 \mathrm{mM}$ IPTG. The cells were harvested by centrifugation, resuspended in $\mathrm{KH}_{2} \mathrm{PO}_{4}$ buffer with $1 \%$ OTG and lysed by sonication with a microtip attachment. Lysate was centrifuged at 25,000 $\mathrm{g}$ for 25 min with supernatant applied to a NiNTA superflow resin (Qiagen) on an Akta FPLC. The fusion protein was cleaved by recombinant tobacco etch virus N1a protease overnight, and final purification was via Waters reverse-phase HPLC. Molecular weight was assayed by either MALDI or ESI-MS.

\section{Cofactor incorporation}

Protein concentration was determined by UV-visible absorbance at $280 \mathrm{~nm}$. Cofactor stocks in DMSO were quantified by mass or using the hemochrome assay ${ }^{51}$ then titrated into protein solution in 0.2-equivalent aliquots during heme-binding assays. Unbound cofactor and DMSO were removed by passing through a PD-10 desalting column (GE). $\mathrm{ZnP}$ and $\mathrm{ZnC}$ were added to the maquette in stochiometric equivalents after one equivalent heme-bound protein maquettes were purified using PD-10 size exclusion columns.

\section{UV-visible, CD and fluorescence spectroscopy}

Protein solutions were prepared in CHES buffer $(20 \mathrm{mM}, 150 \mathrm{mM} \mathrm{KCl}, \mathrm{pH} 9.0)$. Binding was monitored by UV-visible Soret absorbance on a Varian Cary-50 spectrophotometer at room temperature in a 1-cm path quartz cuvette. Secondary structure was monitored by CD spectroscopy (Aviv Model 410) with a 1-mm-path quartz cuvette. Thermal denaturation monitored the ellipticity at $222 \mathrm{~nm}$ every $5{ }^{\circ} \mathrm{C}$ from $5{ }^{\circ} \mathrm{C}$ to $95{ }^{\circ} \mathrm{C}$ after 15 min of equilibration. Melting temperatures were calculated using a Boltzmann equation with one term for each observed transition. 


\section{NMR spectroscopy}

${ }^{15} \mathrm{~N}$-labeled lyophilized protein was dissolved in $50 \mathrm{mM} \mathrm{KH}_{2} \mathrm{PO}_{4}$, $\mathrm{pH} 7.9$, and concentrated using an Amicon 3000 MWCO filter. Cofactor in DMSO- $d_{6}$ was added and purified by PD-10. ${ }^{1} \mathrm{H}-{ }^{15} \mathrm{~N}$ heteronuclear single quantum correlation spectra were recorded on a Bruker $750 \mathrm{MHz}$ magnet at $25^{\circ} \mathrm{C}$.

\section{Flavomaquette preparation}

Cysteine was coupled to 8-bromoriboflavin by adding a fivefold molar excess of flavin with $2 \mathrm{mM}$ DTT (final concentrations) in 30\% (v/v) DMF in $20 \mathrm{mM} \mathrm{KH}_{2} \mathrm{PO}_{4}$ and $100 \mathrm{mM} \mathrm{KCl}$, $\mathrm{pH} 7.5$, followed by stirring overnight at room temperature protected from light. Unbound flavin was removed using a desalting PD-10 column, and the eluates were purified by reverse-phase HPLC, flash frozen in liquid nitrogen and lyophilized. After redissolving in $20 \mathrm{mM} \mathrm{KH}_{2} \mathrm{PO}_{4}, 100 \mathrm{mM} \mathrm{KCl}, \mathrm{pH}$ 7.5, flavin incorporation was confirmed by MALDI MS and UV-visible spectroscopy (absorption bands at $475 \mathrm{~nm}$ ). Hemin was added in twofold excess and stirred for $10 \mathrm{~min}$ at room temperature. Excess hemin was removed using a PD-10 column, and incorporation was confirmed via Soret peak formation at $409 \mathrm{~nm}$.

\section{Oxygen binding}

Maquette protein with heme was degassed for $1 \mathrm{~h}$ under argon while stirring and then reduced with minimal dithionite (no visible $350 \mathrm{~nm}$ excess dithionite peak), followed by cannula transfer to a drive syringe in an OLIS RSM-1000 stopped-flow spectrophotometer taking full visible spectra each millisecond. The second stopped-flow drive syringe was filled with oxygen saturated buffer. A water bath kept all of the solutions at $15^{\circ} \mathrm{C}$. Mixing time on firing is $\sim 1 \mathrm{~ms}$. Multiple spectroscopic species were determined using SVD analysis included in the OLIS Globalworks software. Individual wavelengths were chosen for further kinetic analysis.

\section{Superoxide detection}

Argon-saturated and reduced protein was rapidly mixed with air-saturated $30 \mu \mathrm{M} 2-$ methyl-6-(4-methoxyphenyl)-3, 7-dihydroimidazo[1,2-a]pyrazin-3-one hydrochloride

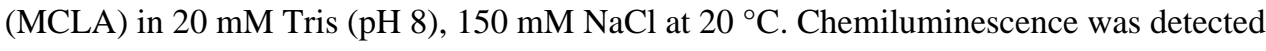
using an Olis stopped-flow by photomultiplier. Signals were integrated and normalized to reduced heme absorbance at $558 \mathrm{~nm}$.

\section{Transient absorption spectroscopy}

A 150-W projector lamp (Cuda Products Model L-150) with a fluid-filled fiberoptic guide provided side continuous illumination to an anaerobic cuvette with 1-cm path length in an Agilent 8453 diode array spectrometer. Typical concentrations are $1 \mu \mathrm{M}$ of maquette in 20 $\mathrm{mM}$ CHES, $150 \mathrm{mM} \mathrm{KCl}, \mathrm{pH} 9.0$, titrated with 1 equivalent of bound ferric heme or covalently attached flavin with either 0.9 equivalents $\mathrm{ZnP}$ or $0.1 \mathrm{mM}$ aniline/1 mM EDTA, respectively, as the sacrificial electron donor.

For pulsed transient absorption spectroscopy, a Quanta-Ray INDI Nd:YAG laser coupled to a BasiScan nanosecond Optical Parametric Oscillator provided 1- to 20-mJ pulses 
continuously tunable over the visible range. An appropriately timed Xe flash source illuminated split fiber optic cables probing sample (laser pumped) and reference (not pumped) regions of an anaerobic cuvette. The two probe beams were collected by two fiber optic bundles, each flattened into a single line of fibers at the entrance slit of an Acton SP-2156 spectrograph. The two fiber images at the exit monochrometer slit were focused on a Princeton Instruments PiMax-3 ICCD camera that allows simultaneous exposures of both sample and reference spectra from a few nanoseconds to seconds at the desired pump or probe delay times set by a Stanford Research System DG 535 digital delay generator. A ThorLabs beam shutter allows the $10-\mathrm{Hz}$ laser rep rate to be lowered to second timescales for the slowest experiments. Illumination of $1 \mu \mathrm{M}$ maquette protein in anaerobic buffer (20 $\mathrm{mM}$ CHES, $150 \mathrm{mM} \mathrm{KCl}, \mathrm{pH} 9.0$ ) used $16 \mathrm{nM}$ catalase, $80 \mathrm{nM}$ glucose oxidase and $1 \mathrm{mM}$ glucose to maintain anaerobicity for the duration of the data collection. Sacrificial electron donors, when present, were as described above.

\section{Heme extinction coefficient determination}

Heme was titrated to excess, and the complex was purified on a PD-10 size exclusion column to remove unbound chromophore. This maquette-heme complex was diluted to several different final concentrations, an absorbance spectrum of each was recorded, and the samples were sent for quantitative iron analysis by ICP-OES (Chemical Solutions Ltd., Mechanicsburg, PA). The reported concentrations of iron were plotted against the absorbance at $\lambda_{\max }(412 \mathrm{~nm})$ to generate an extinction coefficient $\varepsilon=109,700 \mathrm{M}^{-1} \mathrm{~cm}^{-1}$ for the oxidized heme (Supplementary Fig. 1). The absorbance spectrum of a given heme quantity bound to $\mathrm{J}$ is identical to that in $\mathrm{A}$ of the same concentration, and there is no evidence of differing absorbance properties at the two binding sites of A. After reanalyzing titration data using the experimentally determined extinction coefficient, we concluded that the most accurate heme stock concentration analysis is indeed the pyridine hemichromederived figure calculated by the difference of reduced and oxidized absorbance values.

\section{Redox potentiometry}

Redox titrations were performed in combination with UV-visible monitoring. Samples of typically 5-20 $\mu \mathrm{M}$ were monitored electrochemically by a calomel electrode (Radiometer Analytical). The change from oxidized to reduced was monitored by the change in absorbance at the Q-band region of the bis-histidine ligated porphyrin (typically $556 \mathrm{~nm}$ ). These titrations were done anaerobically under a constant stream of Ar that had been scrubbed of residual $\mathrm{O}_{2}$ by bubbling through a solution of $\mathrm{VOSO}_{4}$ reduced with $\mathrm{Zn}$ and $\mathrm{H}_{2} \mathrm{SO}_{4}$. The $E_{\mathrm{h}}$ was modulated by 1- to 3- $\mu$ injections of a freshly prepared sodium dithionite solution when lowering the potential or with a potassium ferricyanide solution when trying to increase the potential. The following redox mediators were used: anthraquinone-2-sulfonate $(20 \mu \mathrm{M})$, benzyl viologen $(10 \mu \mathrm{M})$, methyl viologen $(10 \mu \mathrm{M})$, duroquinone $(10 \mu \mathrm{M})$, indigo trisulfonate $(10 \mu \mathrm{M})$, phenazine $(10 \mu \mathrm{M})$, pyocyanin $(10 \mu \mathrm{M})$ and hydroxynapthoquinone $(10 \mu \mathrm{M})$. The data was then fitted to a Nernst equation with $n=$ 1 fixed. 


\section{$\mathrm{K}_{\mathrm{D}}$ determination}

$K_{\mathrm{D}}$ values were determined by the following method. To $1 \mathrm{ml}$ of protein solution, the cofactor being studied was added in 0.2 equivalent aliquots, and a spectrum was taken each time. This was typically done for up to 5 equivalents of cofactor. The data was fitted to the following equation (1):

$$
\mathrm{A}=H_{\text {tot }} \varepsilon_{\text {free }}+\left(\varepsilon_{\text {bound }}-\varepsilon_{\text {free }}\right) \frac{\left(K_{D}+P_{t o t}+H_{t o t}-\sqrt{\left(K_{D}+P_{t o t}+H_{t o t}\right)^{2}-4 P_{t o t} H_{t o t}}\right)}{2}
$$

where $H_{\text {tot }}$ is the total cofactor present in the sample, $P_{\text {tot }}$ is the total protein concentration, $\varepsilon_{\text {free }}$ is the extinction coefficient of the free cofactor, and $\varepsilon_{\text {bound }}$ is the extinction coefficient of the bound cofactor (Supplementary Fig. 1).

\section{Low temperature spectroscopy}

UV-visible spectra were taken on Varian Cary 50 Bio Spectrometer from 200-800 nm of 5 $\mu \mathrm{M}$ protein in $25 \mathrm{mM}$ sodium phosphate, $\mathrm{pH} 8$, and $30 \%$ ethylene glycol at $-15^{\circ} \mathrm{C}$. Sample was degassed with argon for $90 \mathrm{~min}$ for the oxidized spectrum and then reduced with minor excess dithionite by titration. Carbon monoxide was bubbled for $5 \mathrm{~min}$ followed by $5 \mathrm{~min}$ of bubbling with oxygen. Carbon monoxide was flashed off using a Dolan Jenner Model 180 fiberoptic quartz halogen light source. Oxygen was bubbled again, and the sample was flashed for oxyferrous heme spectra acquisition.

\section{Data analysis}

Data were analyzed using either KaleidaGraph software version 4.1 .3 or Origin version 8.1. Single exponential fits were also taken from these programs. SVD of kinetic data was performed using Olis Global Works software version 4.6.

All of the kinetic traces in Figure 4 were fit to a single exponential in Kaleidagraph, and the error was taken from this fit. Oxyferrous experiments were done in triplicate, and the data were averaged for analysis. Superoxide experiments were performed 15 times, and the shown signal traces are the normalized average. Electron transfer experiments between $\mathbf{A}$ and cytochrome $c$ were performed in triplicate, and the data were averaged for the fit and SVD analysis.

\section{Supplementary Material}

Refer to Web version on PubMed Central for supplementary material.

\section{Acknowledgments}

In this research, the US National Institutes of Health (NIH)-General Medical Institutes (RO1 GM 41048) funded the design and development of the maquette proteins $\mathbf{A}, \mathbf{B}, \mathbf{F}, \mathbf{G}$ and $\mathbf{H}$, including gene design, cloning, protein expression, purification and characterization; it also funded the thermal stability measurements using $\mathrm{CD}$ and demonstrations of control of oxygen binding and redox chemistry. Basic to these developments was NMR spectroscopy performed by M.A.S., K.G.V. and A.J.W., supported by NIH United States Public Health Service grants DK39806 and GM102477 to A.J.W. The US Department of Energy, Office of Basic Energy Sciences, Division of Materials Sciences and Engineering (DE-FG02-05ER46223) funded the synthesis and characterization of flavins and also the design, expression, purification and characterization of $\mathbf{C}, \mathbf{K}, \mathbf{J}$ protein maquettes promoting 
light-activated charge separation and oxidation-reduction using flavin and $\mathrm{Zn}$ - and $\mathrm{Fe}$ - tetrapyrroles as cofactors. The US Department of Energy Office of Basic Energy Sciences, Energy Frontier Research Center (PARC) (DE-SC 0001035 to P.L.D. and C.C.M.) funded development of light excitation energy transfer in maquettes ( $\mathbf{L}$ and its mutants), synthesis and purification of $\mathrm{Zn}$ pyropheophoribide a and covalent attachments of Alexa Fluor to the maquettes. In this work, the synthetic chlorin $\mathrm{ZnC}$ was a generous gift from O. Mass and J.S. Lindsey at North Carolina State University.

\section{References}

1. Fischer, E. Nobel Lectures, Chemistry 1901-1921. Nobelstiftelsen, editor. Vol. 1. Elsevier; Amsterdam: 1966. p. 21-35.

2. Brustad EM, Arnold FH. Optimizing non-natural protein function with directed evolution. Curr. Opin. Chem. Biol. 2011; 15:201-210. [PubMed: 21185770]

3. Baker D. An exciting but challenging road ahead for computational enzyme design. Protein Sci. 2010; 19:1817-1819. [PubMed: 20717908]

4. Prabhulkar S, Tian H, Wang XT, Zhu JJ, Li CZ. Engineered proteins: redox properties and their applications. Antioxid. Redox Signal. 2012; 17:1796-1822. [PubMed: 22435347]

5. Edelman GM, Gally JA. Degeneracy and complexity in biological systems. Proc. Natl. Acad. Sci. USA. 2001; 98:13763-13768. [PubMed: 11698650]

6. Lichtenstein BR, et al. Engineering oxidoreductases: maquette proteins designed from scratch. Biochem. Soc. Trans. 2012; 40:561-566. [PubMed: 22616867]

7. Regan L, DeGrado WF. Characterization of a helical protein designed from first principles. Science. 1988; 241:976-978. [PubMed: 3043666]

8. Page CC, Moser CC, Chen X, Dutton PL. Natural engineering principles of electron tunnelling in biological oxidation-reduction. Nature. 1999; 402:47-52. [PubMed: 10573417]

9. Robertson DE, et al. Design and synthesis of multi-heme proteins. Nature. 1994; 368:425-432. [PubMed: 8133888]

10. Sharp RE, Moser CC, Rabanal F, Dutton PL. Design, synthesis, and characterization of a photoactivatable flavocytochrome molecular maquette. Proc. Natl. Acad. Sci. USA. 1998; 95:10465-10470. [PubMed: 9724726]

11. Shifman JM, Moser CC, Kalsbeck WA, Bocian DF, Dutton PL. Functionalized de novo designed proteins: mechanism of proton coupling to oxidation/reduction in heme protein maquettes. Biochemistry. 1998; 37:16815-16827. [PubMed: 9843452]

12. Grosset AM, Gibney BR, Rabanal F, Moser CC, Dutton PL. Proof of principle in a de novo designed protein maquette: an allosterically regulated, charge-activated conformational switch in a tetra-a-helix bundle. Biochemistry. 2001; 40:5474-5487. [PubMed: 11331012]

13. Anderson JLR, Koder RL, Moser CC, Dutton PL. Controlling complexity and water penetration in functional de novo protein design. Biochem. Soc. Trans. 2008; 36:1106-1111. [PubMed: 19021506]

14. Koder RL, et al. Design and engineering of an $\mathrm{O}_{2}$ transport protein. Nature. 2009; 458:305-309. [PubMed: 19295603]

15. Bender GM, et al. De novo design of a single-chain diphenylporphyrin metalloprotein. J. Am. Chem. Soc. 2007; 129:10732-10740. [PubMed: 17691729]

16. Ku J, Schultz PG. Alternate protein frameworks for molecular recognition. Proc. Natl. Acad. Sci. USA. 1995; 92:6552-6556. [PubMed: 7604031]

17. Predki PF, Regan L. Redesigning the topology of a four-helix-bundle protein: monomeric Rop. Biochemistry. 1995; 34:9834-9839. [PubMed: 7543279]

18. Westerlund K, et al. Making a single-chain four-helix bundle for redox chemistry studies. Protein Eng. Des. Sel. 2008; 21:645-652. [PubMed: 18755707]

19. Huang SS, Gibney BR, Stayrook SE, Dutton PL, Lewis M. X-ray structure of a Maquette scaffold. J. Mol. Biol. 2003; 326:1219-1225. [PubMed: 12589764]

20. Aurora R, Rose GD. Helix capping. Protein Sci. 1998; 7:21-38. [PubMed: 9514257]

21. Koder RL, et al. Native like structure in designed four a-helix bundles driven by buried polar interactions. J. Am. Chem. Soc. 2006; 128:14450-14451. [PubMed: 17090015] 
22. Caffrey MS, Cusanovich MA. Site-specific mutagenesis studies of cytochromes $c$. Biochim. Biophys. Acta. 1994; 1187:277-288. [PubMed: 7918530]

23. Davies AM, et al. Redesign of the interior hydrophilic region of mitochondrial cytochrome $c$ by site-directed mutagenesis. Biochemistry. 1993; 32:5431-5435. [PubMed: 8388720]

24. Trent JT, Hvitved AN, Hargrove MS. A model for ligand binding to hexacoordinate hemoglobins. Biochemistry. 2001; 40:6155-6163. [PubMed: 11352753]

25. Kiger L, et al. Electron transfer function versus oxygen delivery: a comparative study for several hexacoordinated globins across the animal kingdom. PLoS ONE. 2011; 6:e20478. [PubMed: 21674044]

26. Hamdane D, et al. Hyperthermal stability of neuroglobin and cytoglobin. FEBS J. 2005; 272:20762084. [PubMed: 15819897]

27. Fago A, Mathews AJ, Moens L, Dewilde S, Brittain T. The reaction of neuroglobin with potential redox protein partners cytochrome $b_{5}$ and cytochrome $c$. FEBS Lett. 2006; 580:4884-4888. [PubMed: 16914148]

28. Margoliash E, Bosshard HR. Guided by electrostatics, a textbook protein comes of age. Trends Biochem. Sci. 1983; 8:316-320.

29. Moser CC, Dutton PL. Cytochrome $c$ and $c_{2}$ binding dynamics and electron transfer with photosynthetic reaction center protein and other integral membrane redox proteins. Biochemistry. 1988; 27:2450-2461. [PubMed: 2838074]

30. Ku HH, Brunk UT, Sohal RS. Relationship between mitochondrial superoxide and hydrogenperoxide production and longevity of mammalianspecies. Free Radic. Biol. Med. 1993; 15:621627. [PubMed: 8138188]

31. Muir Wood P. The redox potential of the system oxygen—superoxide. FEBS Lett. 1974; 44:22-24. [PubMed: 4855030]

32. Zhang L, Andersen EME, Khajo A, Magliozzo RS, Koder RL. Dynamic factors affecting gaseous ligand binding in an artificial oxygen transport protein. Biochemistry. 2013; 52:447-455. [PubMed: 23249163]

33. Cross AR, Parkinson JF, Jones OTG. Mechanism of the superoxide-producing oxidase of neutrophils $-\mathrm{O}_{2}$ is necessary for the fast reduction of cytochrome $b_{245}$ by NADPH. Biochem. J. 1985; 226:881-884. [PubMed: 2985050]

34. Lin C, et al. Association of flavin adenine-dinucleotide with the Arabidopsis blue-light receptor Cry1. Science. 1995; 269:968-970. [PubMed: 7638620]

35. Aubert C, Vos MH, Mathis P, Eker AP, Brettel K. Intraprotein radical transfer during photoactivation of DNA photolyase. Nature. 2000; 405:586-590. [PubMed: 10850720]

36. Muthiah C, Ptaszek M, Nguyen TM, Flack KM, Lindsey JS. Two complementary routes to 7substituted chlorins. Partial mimics of chlorophyll b. J. Org. Chem. 2007; 72:7736-7749. [PubMed: 17803319]

37. Moser CC, Anderson JL, Dutton PL. Guidelines for tunneling in enzymes. Biochim. Biophys. Acta. 2010; 1797:1573-1586. [PubMed: 20460101]

38. Moser CC, Keske JM, Warncke K, Farid RS, Dutton PL. Nature of biological electron transfer. Nature. 1992; 355:796-802. [PubMed: 1311417]

39. Massey V, Stankovich M, Hemmerich P. Light-mediated reduction of flavoproteins with flavins as catalysts. Biochemistry. 1978; 17:1-8. [PubMed: 618535]

40. Grzyb J, et al. Empirical and computational design of iron-sulfur cluster proteins. Biochim. Biophys. Acta. 2012; 1817:1256-1262. [PubMed: 22342202]

41. Reedy CJ, Gibney BR. Heme protein assemblies. Chem. Rev. 2004; 104:617-649. [PubMed: 14871137]

42. Monien BH, Drepper F, Sommerhalter M, Lubitz W, Haehnel W. Detection of heme oxygenase activity in a library of four-helix bundle proteins: towards the de novo synthesis of functional heme proteins. J. Mol. Biol. 2007; 371:739-753. [PubMed: 17585935]

43. Patel SC, Hecht MH. Directed evolution of the peroxidase activity of a de novo-designed protein. Protein Eng. Des. Sel. 2012; 25:445-452. [PubMed: 22665824] 
44. Smith BA, Hecht MH. Novel proteins: from fold to function. Curr. Opin. Chem. Biol. 2011; 15:421-426. [PubMed: 21474363]

45. Fry HC, Lehmann A, Saven JG, DeGrado WF, Therien MJ. Computational design and elaboration of a de novo heterotetrameric a-helical protein that selectively binds an emissive abiological (porphinato)zinc chromophore. J. Am. Chem. Soc. 2010; 132:3997-4005. [PubMed: 20192195]

46. Reig AJ, et al. Alteration of the oxygen-dependent reactivity of de novo Due Ferri proteins. Nat. Chem. 2012; 4:900-906. [PubMed: 23089864]

47. Röthlisberger D, et al. Kemp elimination catalysts by computational enzyme design. Nature. 2008; 453:190-195. [PubMed: 18354394]

48. Miner KD, et al. A designed functional metalloenzyme that reduces $\mathrm{O}_{2}$ to $\mathrm{H}_{2} \mathrm{O}$ with over one thousand turnovers. Angew. Chem. Int. Ed. Engl. 2012; 51:5589-5592. [PubMed: 22539151]

49. Gibney BR, Mulholland SE, Rabanal F, Dutton PL. Ferredoxin and ferredoxin-heme maquettes. Proc. Natl. Acad. Sci. USA. 1996; 93:15041-15046. [PubMed: 8986760]

50. Fisher MA, McKinley KL, Bradley LH, Viola SR, Hecht MH. De novo designed proteins from a library of artificial sequences function in Escherichia coli and enable cell growth. PLoS ONE. 2011; 6:e15364. [PubMed: 21245923]

51. Berry EA, Trumpower BL. Simultaneous determination of hemes a, b and $\mathrm{c}$ from pyridine hemochrome spectra. Anal. Biochem. 1987; 161:1-15. [PubMed: 3578775] 
a

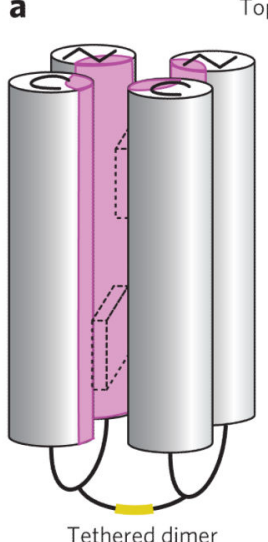

Tethered dimer

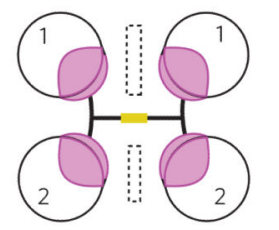

Nonpolar: A, I, F, L, W

Polar: $\mathrm{D}, \mathrm{E}, \mathrm{N}, \mathrm{K}, \mathrm{Q}$ b Diversity

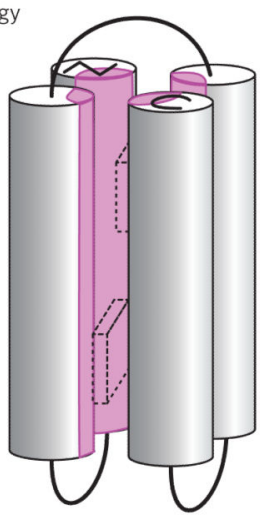

Single chain

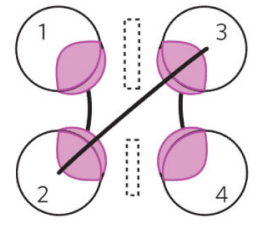

Cofactor binding: $\mathrm{C}, \mathrm{H}$
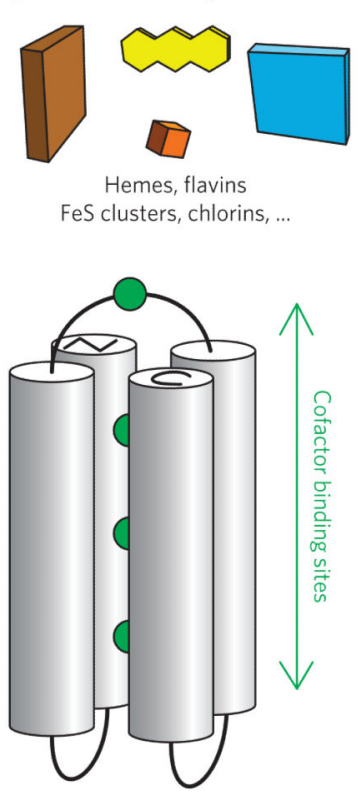

Figure 1. Helical bundle topology and cofactor insertion

(a) Two perspectives of a homodimeric 4-a-helical maquette tethered by a disulfide bond. The tethered dimer is converted to a single chain form (center) by linking helices 2 and 3 , allowing the sequence of all four of the helices to be different. Assembly exploits binary patterning with nonpolar amino acids on the interior (purple) and polar amino acids on the exterior (gray). (b) diversity in function is accomplished by securing a variety of cofactors (top) to various sites (bottom) within the maquette using appropriate cofactor anchoring amino acids (green). 


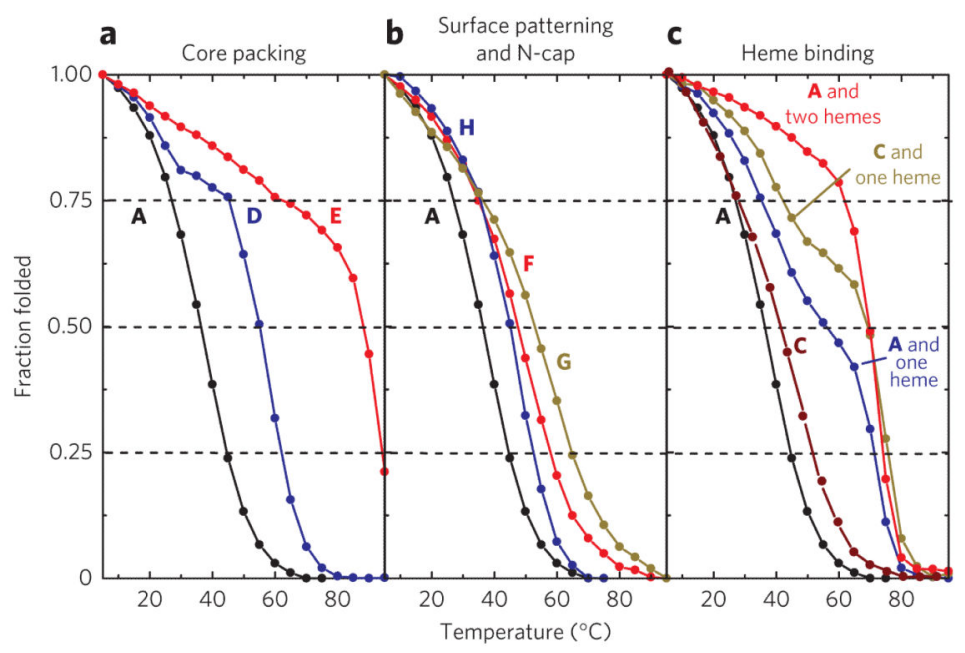

Figure 2. Secondary and tertiary structuring in maquettes

Thermal denaturation of a-helical content monitored as a loss of cd at $222 \mathrm{~nm}$. (a) core packing stabilization of the apo-maquette by replacing histidines in $\mathbf{a}$ with alanines in $\mathbf{D}$ and phenylalanines in E. (b) effects of modifying sequence a to include charge patterning, intrahelical salt bridges $(\mathbf{F}, \mathbf{g})$ or an $\mathrm{N}$-cap $(\mathbf{H})$. (c) The impact of one- and two-heme ligation on the thermal stability of $\mathbf{a}$ and $\mathbf{c}$, which can only ligate a single heme. All of the cd experiments were performed with $20 \mu \mathrm{m}$ protein in $150 \mathrm{~mm} \mathrm{Kcl,} 20 \mathrm{~mm} \mathrm{cHeS}$ at pH 9 with the cd signal amplitude normalized to unity at $5^{\circ} \mathrm{c}$. Thermal melts show substantial reversibility with $85 \%$ of heme binding and protein helicity maintained after exposing a to $95^{\circ} \mathrm{c}$ for $30 \mathrm{~min}$, then recooling to $25^{\circ} \mathrm{c}$ (Supplementary Fig. 35). Some aggregation or degradation may occur at prolonged near boiling temperatures. All of the cd melt data was performed once with an averaging time of $30 \mathrm{~s}$ at each temperature $\left(5^{\circ} \mathrm{c}\right.$ to $95^{\circ} \mathrm{c}$ in $5 \mathrm{~J}$ increments). For all melts, $222 \mathrm{~nm}$ was monitored. data were collected once, and the error associated with the numbers $\left( \pm 5^{\circ}\right)$ was taken from the error provided by the fitting program. 


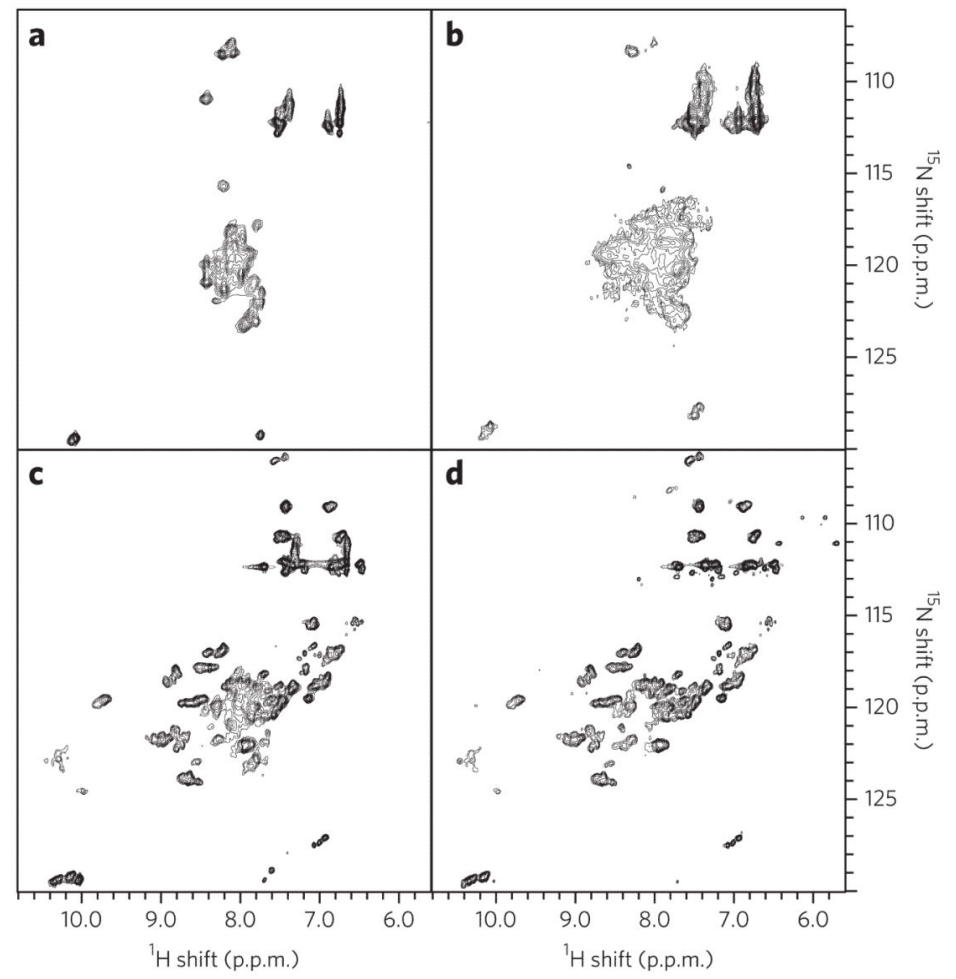

Figure 3. $750 \mathrm{mHz}{ }^{15} \mathrm{~N}$-HSQc showing changes in $\mathrm{NmR}$ spectral dispersion upon heme binding (a) In the absence of cofactor, Nmr resonances of a are relatively undispersed. (b) Addition of two equivalents of heme to the His-free $\mathbf{E}$ is also relatively undispersed. (c) Addition of one equivalent to a induces partial dispersion, indicative of stable structure. (d) Addition of a second equivalent of heme induces further structuring. Nmr was performed with $200 \mu \mathrm{m}$ a in $50 \mathrm{~mm} \mathrm{KH}_{2} \mathrm{Po}_{4}$ and $50 \mathrm{~mm} \mathrm{Kcl}, \mathrm{pH} 7.9$, at $25^{\circ} \mathrm{c}$. 

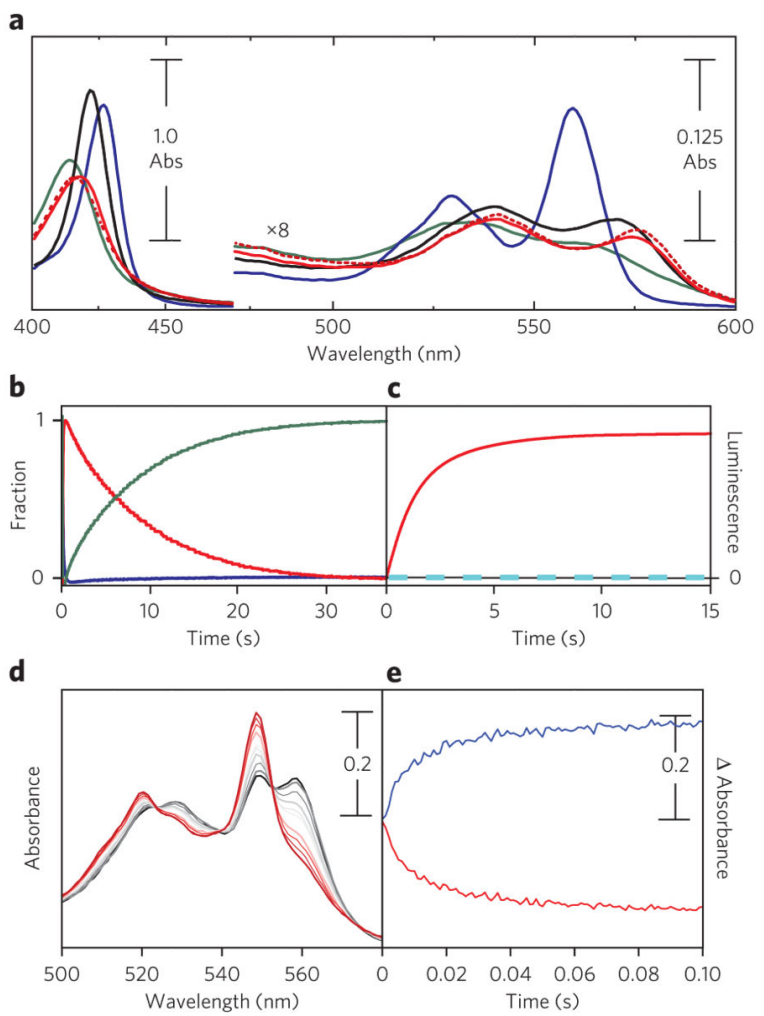

Figure 4. Heme spectra and kinetics of substrate binding and electron transfer

(a) Absorbance (Abs) spectra of $4 \mu \mathrm{m}$ a equipped with two hemes in $20 \mathrm{~mm} \mathrm{cHeS}, 150 \mathrm{~mm}$ $\mathrm{Kcl}, \mathrm{pH}$ 9.0, 30\% (v/v) ethylene glycol. Heme states: blue, ferrous; green, ferric; black, carboxyferrous; red, oxyferrous. Spectra were taken at $-15^{\circ} \mathrm{c}$, where oxyferrous states are stable for $>1 \mathrm{~h}$. Similar spectra are seen at $15^{\circ} \mathrm{c}$ (not shown). dashed red trace shows the one-heme oxyferrous spectrum of a doubled in scale for direct comparison with the twoheme oxyferrous spectrum (solid line). (b) Kinetic measurements were recorded mixing 6 $\mu \mathrm{m}$ ferrous a with oxygen-saturated buffer in Tris buffer $(20 \mathrm{~mm}$ Tris, $20 \mathrm{~mm} \mathrm{Nacl}$, pH 8.0, at $15^{\circ} \mathrm{c}$ ). Heme state populations (blue, ferrous; red, oxyferrous; green, ferric) were computed by deconvoluting the components of the stop-flow spectra, normalizing the oxyferrous maximum $(574 \mathrm{~nm}$ ). (c) detection of superoxide using chemiluminescent probe mclA $(30 \mu \mathrm{m})$ during the stopped-flow mixing of $5 \mu \mathrm{m}$ maquette with air-saturated Tris buffer ( $\mathrm{pH} 8$ ). maquettes shown are the tethered dimer (black), a (blue dashed) and $\mathbf{i}$ (red). (d,e) electron-transfer from partially reduced $9.5 \mu \mathrm{m}$ a with two equivalents of heme to 17 $\mu \mathrm{m}$ cytochrome $c$. Shown in $\mathbf{d}$ are Q-band spectral changes for both proteins from $0 \mathrm{~ms}$ (black) to $30 \mathrm{~ms}$ (red). Peaks at $558 \mathrm{~nm}$ and 548 correspond to the a-bands of ferrous heme in a and cytochrome $c$, respectively. Shown in e are redox kinetics for holo-a and cytochrome $c$ over $100 \mathrm{~ms}$. The black and red traces show relative absorbance changes at the 558-nm ferrous cytochrome $c$ peak and the 548-nm ferrous a peak, respectively, compared to the isosbestic point at $553 \mathrm{~nm}$. experiments were performed in $50 \mathrm{~mm} \mathrm{HePeS}, 120 \mathrm{~mm}$ $\mathrm{Kcl}, \mathrm{pH}$ 8.0. Statistical analysis for all data is in the online methods. 

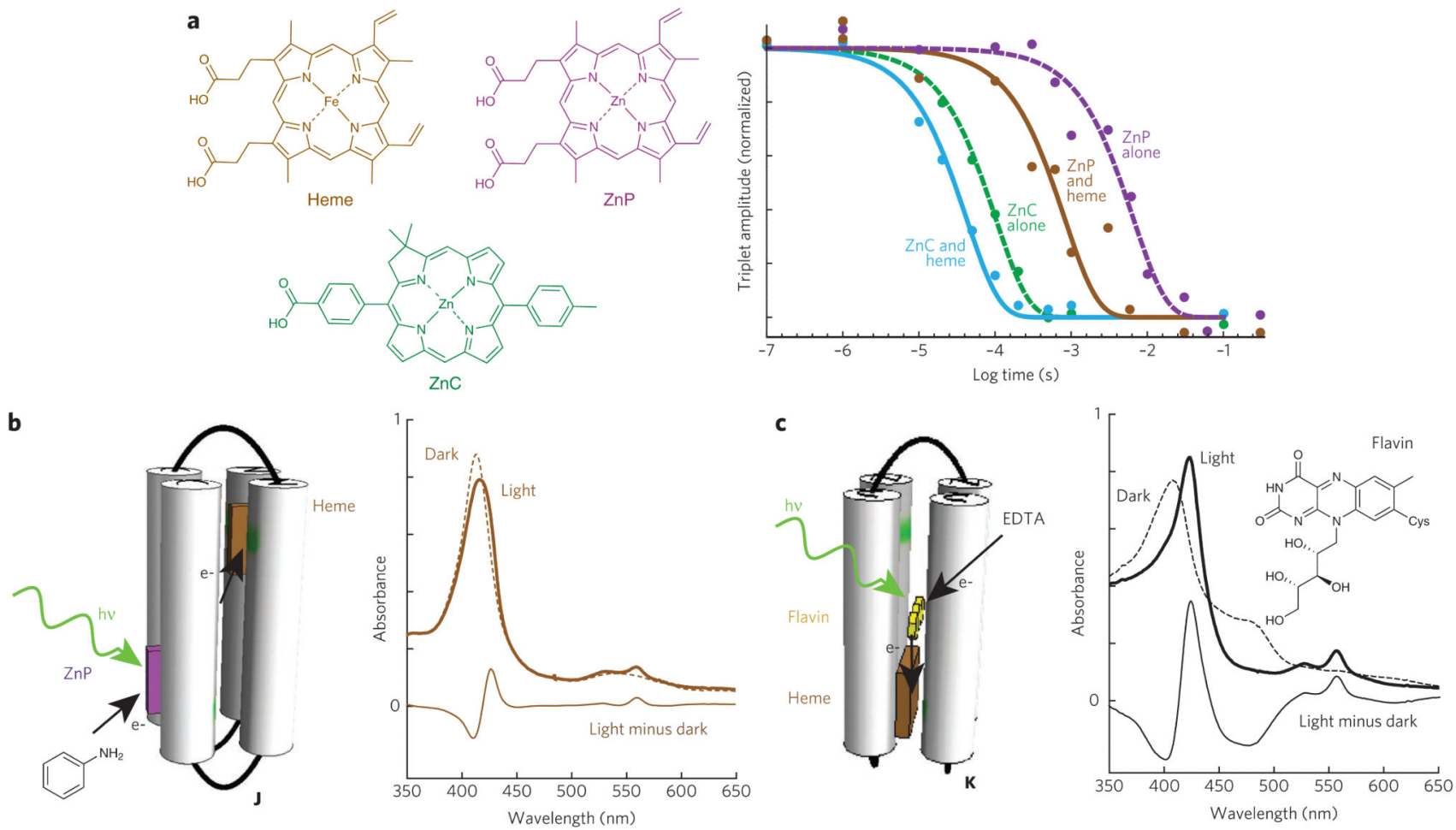

Figure 5. Light activated electron transfer experiments with a protein maquette

(a) Transient absorption spectroscopy of single-chain maquettes binding a variety of cofactors. A laser pulse excites $\mathrm{Zn}$ chlorin (Znc) bound to $\mathbf{c}$ or $\mathrm{Zn}$ protoporphyin IX (ZnP) bound to $\mathbf{J}$, and the decay of the resulting triplet state is tracked in the absorption spectra. Normalized triplet populations are plotted for each system and fitted to single exponential decays. The data for all of these traces were fit to a single exponential function. All of these data have an error of $10 \%$. (b) reduction of heme bound in $8 \mu \mathrm{m} \mathbf{J}$ following photoexcitation of $\mathrm{ZnP}$. dashed and bold traces are absorption spectra of the sample before and after $20 \mathrm{~min}$ of white light illumination, respectively. experiments were performed in $20 \mathrm{~mm} \mathrm{cHeS}, 150$ $\mathrm{mm} \mathrm{Kcl,} \mathrm{pH} 9.0$, and $0.1 \mathrm{~mm}$ aniline. (c) reduction of bound heme following photoexcitation of 8-bromoriboflavin covalently attached to $8 \mu \mathrm{m} \mathrm{K}$. dashed and bold traces show absorption spectra before and after $60 \mathrm{~min}$ of white light illumination, respectively. experiments were performed in $20 \mathrm{~mm} \mathrm{cHeS}, 150 \mathrm{~mm} \mathrm{Kcl}, \mathrm{pH}$ 9.0, and $1 \mathrm{~mm}$ edTA. experiments in $\mathbf{b}$ and $\mathbf{c}$ were done in duplicate. 
Table 1

Single-chain maquette sequences with small variations that site-specifically anchor redox cofactors and test thermal stability

\begin{tabular}{|c|c|c|c|c|c|c|c|c|c|}
\hline \multirow{2}{*}{$\frac{\text { Name }}{A}$} & \multicolumn{6}{|c|}{ Sequence } & \multirow{2}{*}{$\frac{\text { Cofactors }}{1 \text { heme }}$} & \multirow{2}{*}{$\frac{\boldsymbol{E}_{\mathbf{m s}}(\mathbf{m V})}{-260}$} & \multirow{2}{*}{$\frac{\boldsymbol{K}_{\mathbf{D}}(\mathbf{n M})}{<2}$} \\
\hline & G & EIWKQHE & DALQKFE & EALNQFE & DLKQL & GGSGSGSGG & & & \\
\hline & & EIWKQHE & DALQKFE & EALNQFE & DLKQL & GGSGSGSGG & 2 hemes & $-290,-290$ & $<2,<2$ \\
\hline & & EIWKQHE & DALQKFE & EALNQFE & DLKQL & GGSGSGSGG & & & \\
\hline & & EIWKQHE & DALQKFE & EALNQFE & DLKQL & & & & \\
\hline \multirow[t]{4}{*}{ B } & MTPE & QIWKQHE & DALQKFE & EALNQFE & DLKQL & GGSGSGSGG & 2 hemes & ND & ND \\
\hline & & EIWKQHE & DALQKFE & EALNQFE & DLKQL & GGSGSGSGGGG & & & \\
\hline & & EIWKQHE & DALQKFE & EALNQFE & DLKQL & GGSGSGSGG & & & \\
\hline & & EIWKQHE & DALQKFE & EALNQFE & DLKQL & & & & \\
\hline \multirow[t]{4}{*}{ C } & G & EIWKQHE & DALQKFE & EALNQFE & DLKQL & GGSGSGSGG & 1 heme & -260 & 12 \\
\hline & & EIWKQAE & DALQKFE & EALNQFE & DLKQL & GGSGSGSGG & $2 \mathrm{ZnC}$ & ND & $<100$ \\
\hline & & EIWKQHE & DALQKFE & EALNQFE & DLKQL & GGSGSGSGG & 1 heme, 1 & ND & $<100 \quad 800$ \\
\hline & & EIWKQHE & DALQKFE & EALNQFE & DLKQL & & $\mathrm{ZnC}$ & ND & $<100,800$ \\
\hline \multirow[t]{4}{*}{ D } & G & EIWKQAE & DALQKFE & EALNQFE & DLKQL & GGSGSGSGG & N/A & N/A & N/A \\
\hline & & EIWKQAE & DALQKFE & EALNQFE & DLKQL & GGSGSGSGG & & & \\
\hline & & EIWKQAE & DALQKFE & EALNQFE & DLKQL & GGSGSGSGG & & & \\
\hline & & EIWKQAE & DALQKFE & EALNQFE & DLKQL & & & & \\
\hline \multirow[t]{4}{*}{$\mathbf{E}$} & G & EIWKQFE & DALQKFE & EALNQFE & DLKQL & GGSGSGSGG & N/A & N/A & N/A \\
\hline & & EIWKQFE & DALQKFE & EALNQFE & DLKQL & GGSGSGSGG & & & \\
\hline & & EIWKQFE & DALQKFE & EALNQFE & DLKQL & GGSGSGSGG & & & \\
\hline & & EIWKQFE & DALQKFE & EALNQFE & DLKQL & & & & \\
\hline \multirow[t]{4}{*}{$\mathbf{F}$} & G & EIWKQHE & DALQKFE & EALNQFE & DLKQL & GGSGKGSGG & 2 hemes & $-224,-150$ & 20,800 \\
\hline & & EIKQRHE & DALRKFE & EALKRFE & DKKQK & GGSGSGSGG & & & \\
\hline & & EIWKQHE & DALQKFE & EALNQFE & DLKQL & GGSGKGSGG & & & \\
\hline & & EIKQRHE & DALRKFE & EALKRFE & DKKQK & & & & \\
\hline \multirow[t]{4}{*}{ G } & G & EIKRQHE & DALRKFE & EALKRFE & DKKQK & GGSGKGSGG & 1 heme & -150 & 365 \\
\hline & & EIWKRHE & DALRKFE & EALKRFE & DKKQK & GGSGKGSGG & 2 hemes & $-150,-150$ & 365,365 \\
\hline & & EIWKRHE & DALRKFE & EALKRFE & DKKQK & GGSGKGSGG & & & \\
\hline & & EIKRQHE & DALRKFE & EALKRFE & DKKQK & & & & \\
\hline \multirow[t]{4}{*}{$\mathbf{H}$} & MTPE & QIWKQHE & DALQKFE & EALNQFE & DLKQL & GGSGSGSGG & 2 hemes & ND & ND \\
\hline & & EIWKQHE & DALQKFE & EALNQFE & DLKQL & GGSGSGSGG & & & \\
\hline & & EIWKQHE & DALQKFE & EALNQFE & DLKQL & GGSGSGSGG & & & \\
\hline & & EIWKQHE & DALQKFE & EALNQFE & DLKQL & & & & \\
\hline \multirow[t]{2}{*}{ I } & G & EIWKQHA & DALQKFA & EALNQFA & DLKQL & GGSGSGSGG & 2 hemes & ND & ND \\
\hline & & EIWKQHA & DALQKFA & EALNQFA & DLKQL & GGSGSGSGG & & & \\
\hline
\end{tabular}




\begin{tabular}{|c|c|c|c|c|c|c|c|c|c|}
\hline \multirow[t]{3}{*}{ Name } & \multicolumn{6}{|c|}{ Sequence } & \multirow[t]{3}{*}{ Cofactors } & \multirow[t]{3}{*}{$E_{\mathrm{ms}}(\mathrm{mV})$} & \multirow[t]{3}{*}{$K_{\mathrm{D}}(\mathrm{nM})$} \\
\hline & & EIWKQHA & DALQKFA & EALNQFA & DLKQL & GGSGSGSGG & & & \\
\hline & & EIWKQHA & DALQKFA & EALNQFA & DLKQL & & & & \\
\hline \multirow[t]{4}{*}{$\mathbf{J}$} & \multirow[t]{4}{*}{ G } & EIWKQHE & DALQKFE & EALNQFE & DLKQL & GGSGSGSGG & 1 heme & ND & 34 \\
\hline & & EIWKQFE & DALQKFE & EALNQFE & DLKQL & GGSGSGSGG & $2 \mathrm{ZnP}$ & ND & $<100$ \\
\hline & & EIWKQHE & DALQKFE & EALNQFE & DLKQL & GGSGSGSGG & 1 heme $17 \mathrm{nP}$ & ND & $<1002900$ \\
\hline & & EIWKQHE & DALQKFE & EALNQFE & DLKQL & & 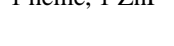 & & \\
\hline \multirow[t]{4}{*}{$\mathbf{K}$} & \multirow[t]{4}{*}{ G } & EIQKQHE & DALQKFE & EALNQFE & DLKQL & GGSGSGSGG & $\begin{array}{l}1 \text { heme, } 1 \\
\text { flavin }\end{array}$ & ND & ND \\
\hline & & EIQKQHE & DFLQKWE & eclnqfe & DLKQL & GGSGSGSGG & & & \\
\hline & & EIQKQAE & DALQKFE & EALNQFE & DLKQL & GGSGSGSGG & & & \\
\hline & & EIQKQHE & DALQKFE & EALNQFE & DLKQL & & & & \\
\hline \multirow[t]{4}{*}{$\mathbf{L}$} & \multirow[t]{4}{*}{ G } & EIWKQHE & DALQKFE & EALNQFE & DLKQL & GGSGSGSGG & $2 \mathrm{ZnP}$ & ND & ND \\
\hline & & EIWKQAE & DALQKFE & EALNQFE & DLKQL & GGSGSGSGG & & & \\
\hline & & EIWKQAE & DALQKFE & EALNQFE & DLKQL & GGSGSGSGG & & & \\
\hline & & EIWKQHE & DALQKFE & EALNQFE & DLKQL & & & & \\
\hline
\end{tabular}

Relatively large changes in the external charge patterning create charge pairing-stabilized $\mathbf{F}$ and $\mathbf{G}$. Sequence changes from the reference singlechain $\mathbf{A}$ are shown in red. For ease of reading, sequences are broken into heptads, which correspond to two turns of the helix; glycine-rich loops are placed at the right. cofactor binding affinity (dissociation constant $\left.K_{\mathrm{D}}\right)$ and redox midpoint potentials $\left(E_{\mathrm{m}}\right)$ of oxidoreductase maquettes are also shown for various tetrapyrroles, including heme, $\mathrm{Zn}$ porphyrin $(\mathrm{ZnP})$ and $\mathrm{Zn}$ chlorin $(\mathrm{ZnC})$. 